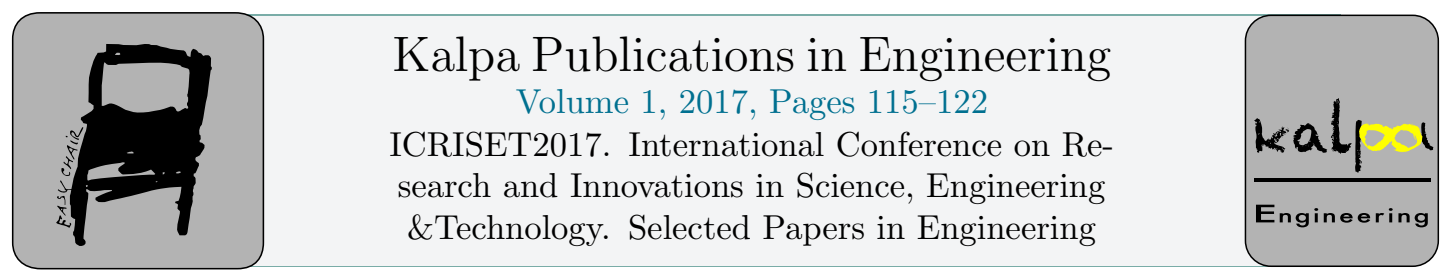

\title{
Defects Analysis Using E Foundry and Flow Simulation for Crank Case Casting
}

\author{
Yogin Vekariya ${ }^{1}$, Trushant Desai ${ }^{1}$, Rakesh Barot ${ }^{1}$, B K Sharma ${ }^{2}$ \\ ${ }^{1}$ Department of Production Engineering \\ BVM Engineering College \\ V.V. Nagar-388120, India \\ yogin439@gmail.com \\ ${ }^{2}$ FINE CAST (GUJ.)PVT LTD. \\ V.U.Nagar,
}

\begin{abstract}
Casting process deals with the metal in the molten state. When the molten metal is poured into the mold box, Smooth and turbulence less flow with appropriate velocity is need to be ensured. Type of flow while pouring the molten metal has significant influence on the end characteristics of casting. Inefficient metal flow can result in error beyond altering the desired characteristics of casting. Dross formation while pouring the metal has direct connection with the type of flow of molten metal. In short, one cannot neglect the flow of molten metal on other hand expecting sound casting formation. Gating characteristics directly deals with the type of flow expected while pouring. To provide desired flow is one of the functions of efficient gating system. But it is very difficult to consider the flow characteristics while actually designing the gating system. Computer technology has taken leap to aid foundry engineer in control of metal flow. Simulation soft-wares have been equipped with provision of flow analysis while designing the Gating system
\end{abstract}

Keywords - Gating system, Flow simulation, Crank case casting. 


\section{Introduction}

Metal casting becomes universal manufacturing process due to its intrinsic characteristics of production from setup work. Many metallic parts found casing is very convenient method to justify as peculiar metal characteristics and simpler design. Casting process involves number of operation that limits inevitability of defects in to process. Number of variable associated with process, makes it prone to defects as other manufacturing process. Casting process can be divided into certain steps which are mould making, metal melting, pouring, solidification and fettling. Defects can be occur into product from any of these steps. Today, mould making process has become semi automated, automated or machine powered and it is become easy to obtain desired metal composition during melting, but solidification which cannot be directly controlled, it can be controlled directly but it amounts to very heavy cost and defects are widely introduces into product from solidification step. Gating system and riser are tools which can help us to indirectly control of solidification characteristics inside the mould cavity. So design of gating system and riser are became prime importance to foundry man. The best way to design gating system and riser design in most economical way is the use of simulation software which gives you freedom with different design without actually performing costlier and time consuming experimental work. Simulation software breaks part into pieces and meshes it piece wise so that process parameters in particular meshed piece can be analyze in unencumbered way. It represents cumulative state of field variable in which we are interested. Therefore, use of simulation is gives you solidification Parameters and also gives metal flow parameters inside the mould which are suffice to obtain casting yield without introducing defects. For the small scale industries as India have in the form of casting industries, it is very costly to perform actual production process on trial basis. They can't have sophisticated instruments for doing research work inside the mould box.

\section{Research Methodology}

Orientation in FINE CAST PVT. LTD

2. Selection of the product for detail study

(32203192) crank case 253

3. Analysis Of frequent defects in the part

4. Indentify the stage and source of the defects

5. Development of the gating system of the product

6. To collect data related to core composition

7. CAD model drafting using CREO 3.0

8. Solidification Simulation of that model for Optimization of Gating system \& Feeder

9. Flow simulation of Model using

Autocast - X

\section{A. About the Company}

Fine Cast It was established in 1973. The Company is ISO 9001: 2008 certified. It is Grey Cast Iron Foundry Industry. Its current customers are Elecon Engg. Co. Ltd., Ingersoll-Rand, Power Build Ltd., Mahindra \& Mahindra etc. It is the mechanized foundry. Fine cast produces Gray Cast Iron of grade 22 to 28 . It produces a daily production of 6-7 tons. 


\section{B. Selection of the Product for Detail Study}

During initial survey it was observed that Crank Case 253 (C.I. grade 24) has higher rate of rejection. So by doing the brain storming with industry officials it was confirmed that Crank Case 253 needs immediate attention for improvement.

\section{Data Analysis}

Data related to the rejection of Crank Case 253 is illustrated in Fig 1 and 2. Based on these data collection Pareto Chart was drawn as in Figure 3 to focus on the most critical defect.

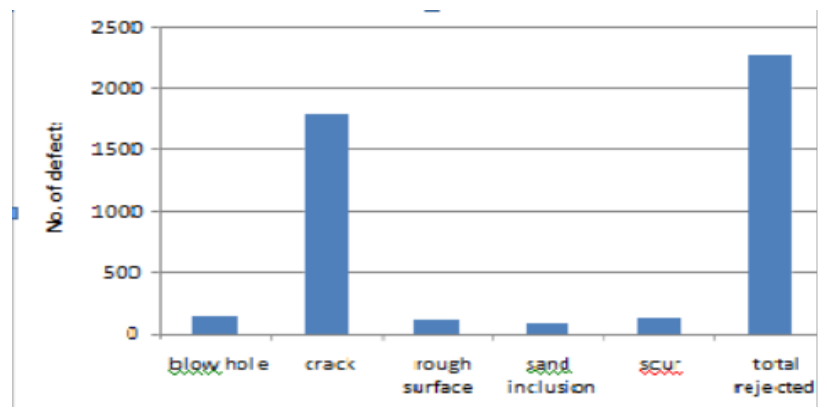

Fig 1 Defects in Crank Case

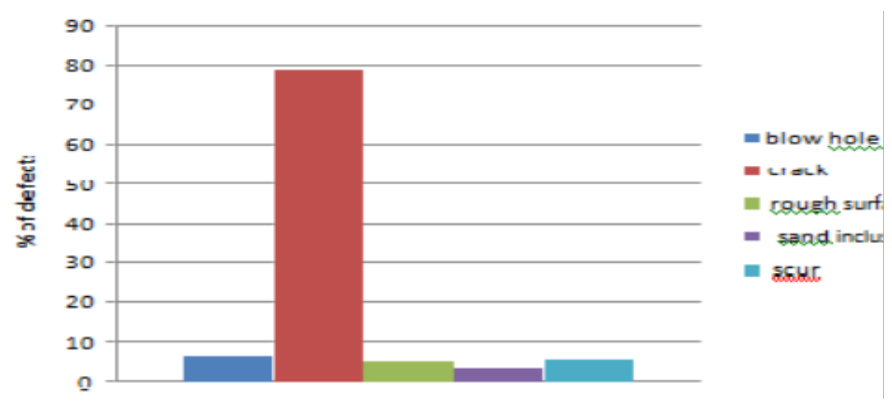

Fig 2 Frequency distribution of defects

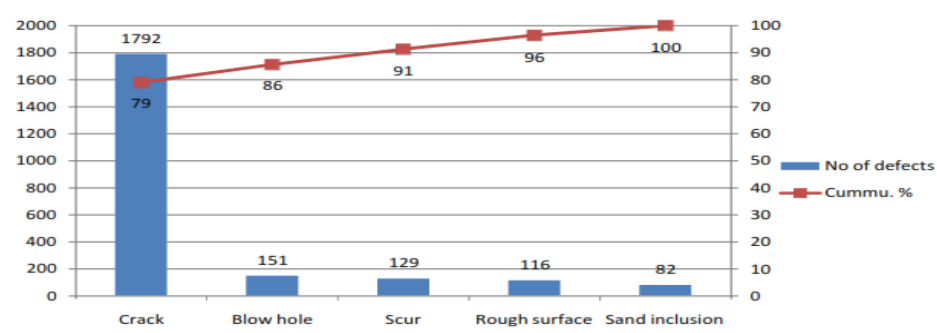

Fig 3 Pareto Chart of defects of Crank Case 253 
From Pareto chart, we can conclude that almost $80 \%$ of causes of rejection are based on defect crack. Therefore there is a greater scope of improvement for working on crack. The interesting thing about the crack results in Crank Case is that it always results on the rim part of Crank Case which is as shown in figure 4.

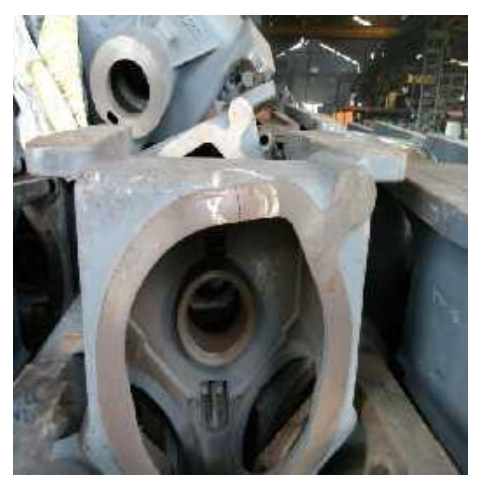

Fig 4 Crack in Crank Case

\section{Current Process Map and Cause \& Effect Diagram}

Figure 5 indicates the current process being followed at the foundry in question. This was done to locate the area of concern which are the likely origin of cracks in the casting.

After studying the current process and through various literature [3] [4] and brainstorming with all the process owners probable causes of cracks were identified and Cause and Effect Diagram was made as in figure 5. Following critical points were noted based on this analysis.

Improper Solidification: Part is removed from the mould very early after pouring. So it has low hardness and it can't sustain the blow of hammer or any other impact, due to this crack may be produced.

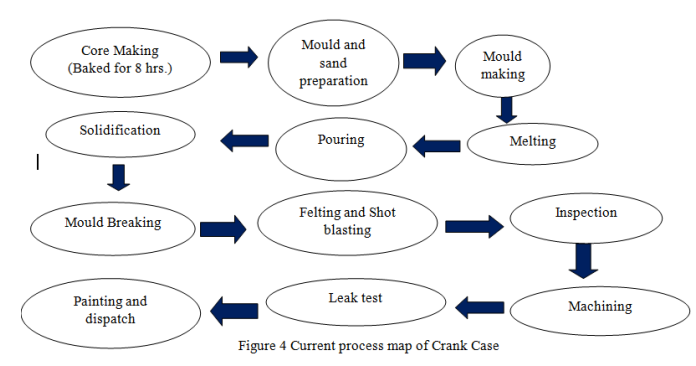

Figure 5 Current Process 
Core is hard or Low Collapsibility: Core is too hard so that at the time of solidification liquid metal try to contract but due to hardness of core it does not allow to cool it due to that residual stress are induced and cracks may produce.

Improper gating system: Efficient gating system aids foundry engineer for obtaining control over process inside the mould but inefficient gating system may worsen the desirable milieu of process. Crack may be result of cumulative effect of improper gating system.

The First reason is the improper solidification. It is difficult and impossible to find out the exact location of the improper solidification in real scenario. To counter this, we need to take help of solidification software simulation. For this the first step is drafting the model in any drawing software. For that we have used Creo 3.0. Figure 6 indicates the solid model and simulation results.

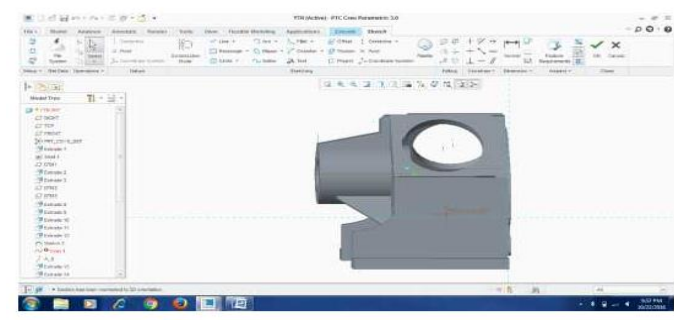

Fig . 6 (a) Solid Model of Crank Case

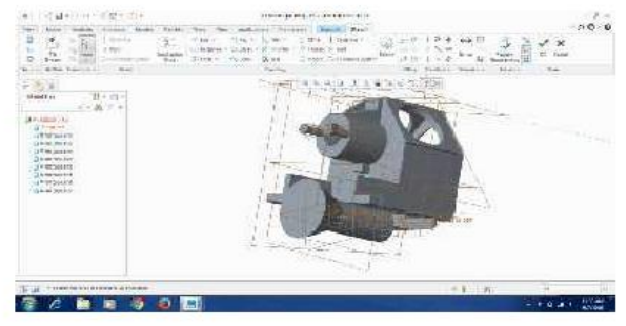

Fig . 6 (b) Crack Case with Gating System

After, solid modeling of crank case with existing gating system we have done thermal simulation in E-foundry [6]. E foundry simulation is online platform of IIT Bombay and known for its prediction of defects related to hotspot and shrinkage. For simulation, the metal, sand type and mesh size (here Gray Cast Iron, Green sand, fine respectively) is specified for results. After brain storming, we noticed one thing that temperature at sprue base located near to the rim is significantly higher than that of rim. So, we developed hypothesis that lower temperature gradient generated because of this hotter sprue base weaken the tensile strength of rim part near to the sprue base compare to that of rim part farthest from sprue base. Also the thickness of rim part near to sprue base is $5 \mathrm{~mm}$ lesser than that of rim part farthest from sprue base. Temperature difference between rim and sprue base with temperature scale is shown in figure 7. 

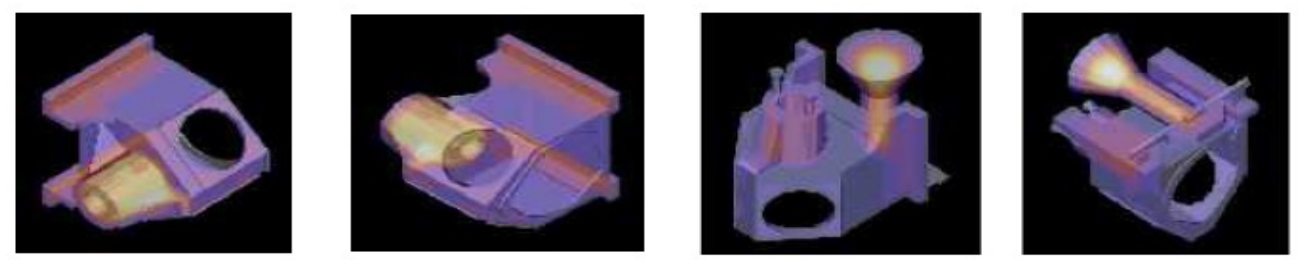

Fig. 7 Simulation Results

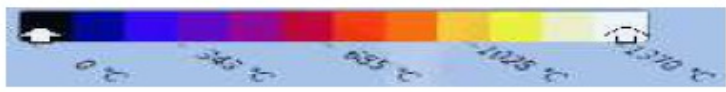

As shown in fig.7 there is no any hot spot and shrinkage related defect occurs in the Crank Case 253 , but the sprue and the sprue base remain hot till the end of solidification so that we have doubt that hotter sprue and base are created the lower heat gradient between it and part ream and hence the ream is remain hot and not enough tough to sustain the hammer blow at time of mould dispatch.

So that reason gives us the link for design new gating system for the Crank Case 253 .

\section{E. Gating system design}

○ Density of Gray Cast Iron, $\rho=7.1 \mathrm{gm} / \mathrm{cm} 3$

- Average section thickness, $\mathrm{T}=1.5 \mathrm{~cm}$

○ Fluidity of Gray Cast Iron $=76.2 \mathrm{~cm}$

- Weight of casting, $\mathrm{W}=32 \mathrm{~kg}$ (including gating system)

○ Nozzle coefficient, c 0.9

○ Gating Ratio= 2:3:1 (from Manufacturing

Process by P N Rao)

- Effective Head, $\mathrm{H}=17 \mathrm{~cm}$

- Cross section of runner and ingate = Rectangular

- Ratio of height to width for runner $=$

1:2(from Manufacturing Process by P N Rao)

- Ratio of height to width for ingate $=1: 4$ (from Manufacturing Process by $\mathrm{P} N$

Rao)

No. of ingates $=2$

New gating system have slightly lesser diameter than exiting one so we did the simulation in the E.foundry and for greater detail we do the simulation both gating system in AutoCast $\mathrm{X}$ [5]. We obtained desired result in solidification simulation performed in Autocast X. 
Table 1 Comparative analysis of gating system

\begin{tabular}{|l|c|c|}
\hline & $\begin{array}{l}\text { Currently } \\
\text { used in Fine } \\
\text { Cast }\end{array}$ & Calculated \\
\hline $\begin{array}{l}\text { Chock Area } \\
\left(\mathrm{cm}^{2}\right)\end{array}$ & - & 2.74 \\
\hline Dia. Of spure $(\mathrm{cm})$ & 2.57 & 1.93 \\
\hline Height of runner $(\mathrm{cm})$ & 1.00 & 1.48 \\
\hline Width of runner $(\mathrm{cm})$ & 2.25 & 2.96 \\
\hline Height of gate $(\mathrm{cm})$ & 0.5 & 0.6 \\
\hline Width of gate $(\mathrm{cm})$ & 3.5 & 2.5 \\
\hline Pouring time $(\mathrm{sec})$ & 15 to 19 & 10 \\
\hline
\end{tabular}

In order to evaluate the gating system with flow characteristics point of view, we did the flow simulation in the Autocast X software. Flow simulation gives you broad view of how the mold cavity fill and we can analyze the velocity of metal flow at every instantaneous time.

In flow simulation we do the time dependent simulation, in this we check the flow of existing and new gating system and also check the velocity generated during the filling of the cavity by molten metal. We also observed that filling time for the new gating system is equal to the existing gating system with same velocity.

Comparison between exiting gating system and newly develop gating system for flow simulations of part with respect to time is given in Table 2 .

\section{Conclusion}

At every instant of mold filling process, velocity in case of newly developed gating system remains lesser than the velocity in case of existing gating system. Lesser velocity obviates any chances of turbulence generation and dross formation while pouring process. So that we can say that newly designed gating system is flawless in point of view of desired flow characteristics.

\section{Acknowledgement}

The authors are grateful to the support provided by FINE CAST (Guj.) PVT. LTD., GIDC, V.U. Nagar, Gujarat, India, in terms of providing the necessary data and other relevant information about their product for the research purpose. The thermal simulation results shown in this paper were obtained by using web resource, efoundry [6], developed by IIT Bombay for online solidification simulation. The simulation results were obtained by using Autocast-X Software under the guidance of Dr. Mayur Sutaria, CSPIT, Changa and we pay special thanks to them.

\section{References}

[1] B. Ravi, "Metal Casting- Computer aided Design \& Analysis", PHI Learning Pvt. Ltd. 
[2] P.N. Rao, "Manufacturing Technology- Foundry, Forming and Welding", Tata Mcgraw Hill Education Pvt. Ltd.

[3] Fernihough, John, Hoebel, Matthias, Konter, Maxim. "Method of removing casting defects". https://www.google.ch/patents/US20050067065

[4] "A textbook of Metal Casting" by Dr. K C Jhon

[5] C. M. Choudhari, B.E. Narkhede, S. K. Mahajan "Casting Design and Simulation of Cover Plate Using AutoCAST-X Software for Defect Minimization with Experimental Validation" (http://www.sciencedirect.com/science/art icle/pii/S221181281400460X)

[6] http://efoundry.iitb.ac.in/ 